\title{
Quantitative Robust Control Engineering: Theory and Experimental Results on Wind Turbines
}

\author{
Mario Garcia-Sanz \\ Automatic Control and Computer Science Department, Public University of Navarre \\ 31006 Pamplona, SPAIN. e-mail: mgsanz@unavarra.es \\ phone: +34948169387
}

\begin{abstract}
This paper presents a summary of the main concepts and references of the Quantitative Feedback Theory (QFT). It is a frequency domain engineering method to design robust controllers. It explicitly emphasises the use of feedback to simultaneously reduce the effects of model plant uncertainty and satisfy performance specifications. QFT has shown a great power to solve real world problems. The second part of the paper describes a new direct drive, variable speed, multipole wind turbine of $1650 \mathrm{~kW}$, and shows some representative experimental results of the wind turbine in different wind speed conditions and controlled by the QFT robust control technique.
\end{abstract}

Key words. QFT control, robust control, wind turbine control, multipole wind turbines.

\section{Introduction}

Much of the current interest in frequency domain robust stability and robust performance dates from the original work of H.W. Bode (1945) [1], and I. Horowitz (1963) [2]. Since then, and during the entire second half of the twentieth century, there has been a tremendous advance in the state-of-the-art of robust frequency domain methods. One of the main techniques, introduced by Prof. Isaac Horowitz in 1959, which characterises closed loop performance specifications against parametric plant uncertainty, mapped into open loop design constraints, became known as Quantitative Feedback Theory (QFT). This paper presents a summary of the main ideas and references of the QFT methodology.

The second part of the paper introduces the new direct drive, variable speed, multipole, wind turbine of 1650 $\mathrm{kW}$ designed by M.Torres [22, 23] and summarises some experimental results of the control system. After several years of multidisciplinary research, the first prototype TWT1650 began to work at Cabanillas Wind Farm (Spain) in August 2001. Since then, a large amount of experimental data has been collected to improve the behaviour of the machine. The controller design has been made using advanced QFT robust control strategies based on the analysis of that information. The paper shows and evaluates some of the most representative experimental results under extreme wind conditions.

\section{QFT}

The Quantitative Feedback Theory (QFT), first introduced by Prof. Isaac Horowitz [3, 18-20] in 1959, is perhaps one of the most successful robust control theories in real-world applications. The awareness of the power of QFT to solve real world problems has evoked the interest and involvement of a greater number of control engineers and researchers [4-17]. The methodology has been used to solve SISO, MISO, and MIMO plants, single and multiple loops, linear and nonlinear processes, lumped and distributed plants, etc.

QFT is an engineering method, which explicitly emphasises the use of feedback to simultaneously reduce the effects of plant uncertainty and satisfy performance specifications. Horowitz's work is deeply rooted in classical frequency response analysis involving Bode diagrams, template manipulations and Nichols Charts (NC). It relies on the observation that the feedback is needed principally when the plant presents model uncertainty or when there are uncertain disturbances acting on the plant.

Frequency domain specifications and desired timedomain responses translated into frequency domain tolerances, lead to the so-called Horowitz-Sidi bounds (or constraints). These bounds serve as a guide for shaping the nominal loop transfer function $L(s)=G(s)$ $\mathrm{P}(\mathrm{s})$, which involves the manipulation of gain, poles and zeros on the controller G(s). On the whole, the QFT main objective is to synthesize (loop-shape) a simple, low-order controller with minimum bandwidth, which satisfies the desired specifications and tackles feedback control problems with robust performance objectives. 
The design process is quite transparent, allowing the designer to see the necessary trade-offs to achieve the closed-loop system specifications. The basic steps of the procedure (see also Fig. 4) are presented in the following sub-sections.

\section{1.- Plant model and Templates generation}

The plant dynamics to be controlled may be described by frequency response data, or by linear or nonlinear transfer functions with mixed (parametric and nonparametric) uncertainty models. It can be defined taking into account the parameter uncertainty of the process at every frequency of interest $\left(\omega_{\mathrm{i}}\right)$, that is to say the plant uncertainty templates, so that $\mathfrak{I} \boldsymbol{P}\left(\mathrm{j} \omega_{\mathrm{i}}\right)=\left\{\mathrm{P}\left(\mathrm{j} \omega_{\mathrm{i}}\right)\right.$, $\left.\omega_{\mathrm{i}} \in \cup \Omega_{\mathrm{k}}\right\}$.

The templates are sets of complex numbers representing the frequency response of the family of uncertain plants at a fixed frequency $\mathfrak{I} \boldsymbol{P}\left(\mathrm{j} \omega_{\mathrm{i}}\right)$, i.e. a template is a projection of the $n$-dimensional parameter space onto the Nichols Chart. Fig.1 represents the QFT-template of a four-parameter plant at $\omega=\omega_{\mathrm{i}}$.

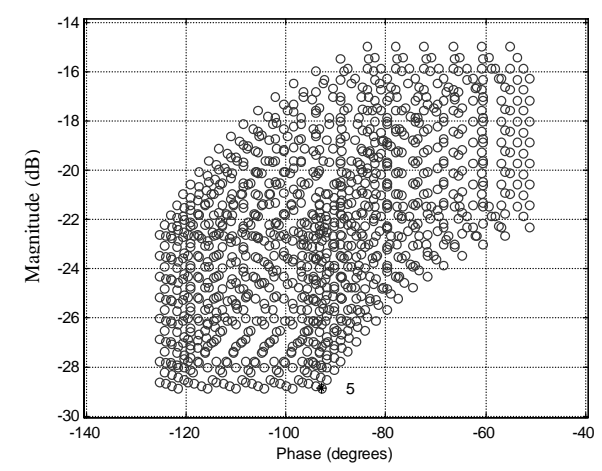

Fig. 1. Template of a four-parameter plant

\section{2.- Performance specifications}

The standard two degree of freedom system which best exemplifies the feedback problem considered in QFT is shown in Fig. 2.

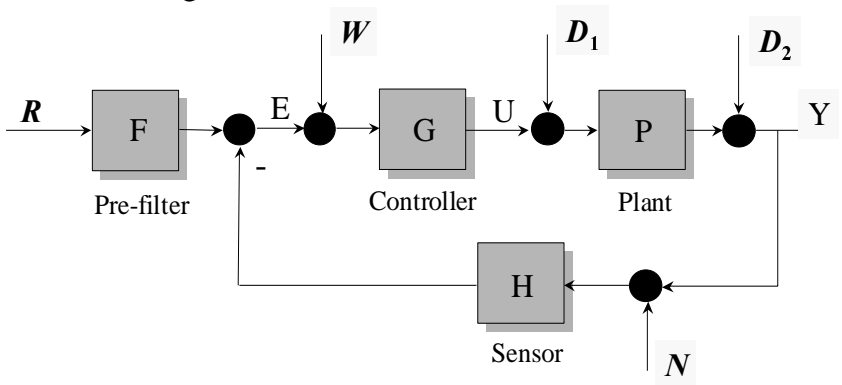

Fig.2. Standard two-degree-of-freedom feedback structure

It includes the set of uncertain plants, $-\mathfrak{I P}\left(j \omega_{\mathrm{i}}\right)=\left\{\mathrm{P}\left(\mathrm{j} \omega_{\mathrm{i}}\right)\right.$, $\left.\omega_{\mathrm{i}} \in \cup \Omega_{\mathrm{k}}\right\}$-, the loop controller -G- and the prefilter -F-, both to be design, and the sensor dynamics -H-. On the other hand, R, E, U, Y and $\mathrm{N}$ are vectors representing respectively: the reference input, the error signal, the controller output, the plant output and the sensor noise input. $\mathrm{W}, \mathrm{D}_{1}$ and $\mathrm{D}_{2}$ are the external disturbance inputs. From the structure we can define the Eqs. (1) to (3),

$$
\begin{aligned}
& Y=\frac{1}{1+P G H} D_{2}+\frac{P}{1+P G H} D_{1}+ \\
& +\frac{P G}{1+P G H}(W+F R)-\frac{P G H}{1+P G H} N \\
& U=\frac{G}{1+P G H}(W+F R)-\frac{G H}{1+P G H}\left(N+D_{2}+P D_{1}\right) \\
& E=-\frac{H}{1+P G H} D_{2}+\frac{P H}{1+P G H} D_{1}+\frac{P G H}{1+P G H} W+ \\
& +\frac{1}{1+P G H} F R-\frac{H}{1+P G H} N
\end{aligned}
$$

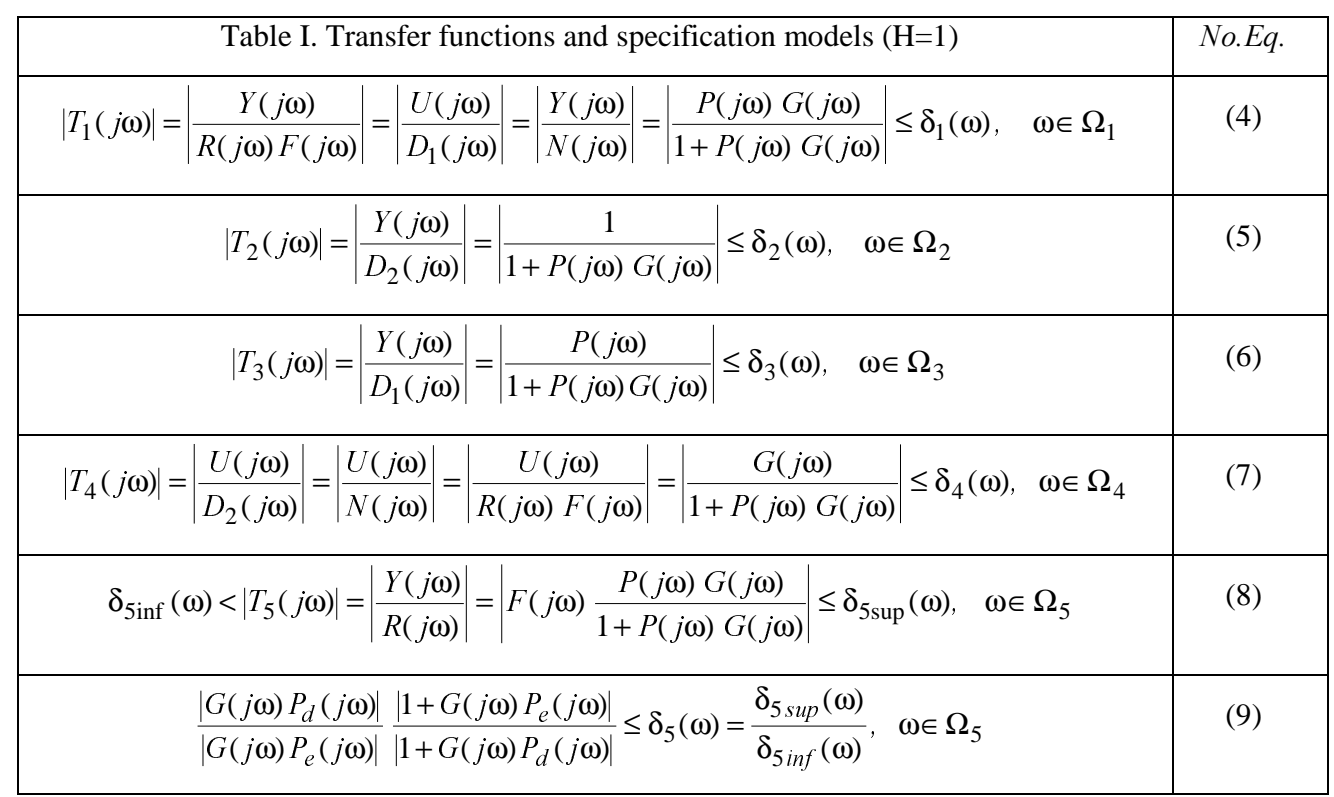


To achieve reliability and robustness, the QFT deals with robust stability margins and robust performance specifications (disturbance rejection, reference tracking, etc) as objectives in terms of the transfer functions of Eqs. (1) to (3) over the frequencies of interest (Table I).

\section{3.- QFT-bounds}

For a nominal plant $\mathrm{P}_{0}(\mathrm{j} \omega)$, member of the family of plants within the uncertainty $\mathfrak{I P}(\mathrm{j} \omega)$, the QFT methodology converts closed-loop system specifications and model plant uncertainty in a set of constrains or bounds (Horowitz-Sidi Bounds) for every frequency of interest that will have to be fulfilled by the nominal open-loop transfer function. They are represented on a Nichols chart. Such a great integration of information in a set of simple curves (the bounds) will allow designing the controller using only a single plant, the nominal plant $\mathrm{P}_{0}$.

The $\omega_{\mathrm{i}}$ plant template, $\boldsymbol{I} \boldsymbol{P}\left(\mathrm{j} \omega_{\mathrm{i}}\right)=\left\{\mathrm{P}\left(\mathrm{j} \omega_{\mathrm{i}}\right)\right\}$, is approximated by a finite set of boundary plants $\left\{P_{r}\left(j \omega_{i}\right)\right.$, $\mathrm{r}=1, \ldots, \mathrm{m}\}$. Each plant can be expressed in its polar form as $\mathrm{P}_{\mathrm{r}}\left(\mathrm{j} \omega_{\mathrm{i}}\right)=\mathrm{p}\left(\omega_{\mathrm{i}}\right) \mathrm{e}^{\mathrm{j} \theta}\left(\omega_{\mathrm{i}}\right)=\mathrm{p} \angle \theta$, and likewise the controller polar form is $\mathrm{G}\left(\mathrm{j} \omega_{\mathrm{i}}\right)=\mathrm{g}\left(\omega_{\mathrm{i}}\right) \mathrm{e}^{\mathrm{j} \phi}=\mathrm{g} \angle \phi$. The controller phase $\phi$ varies from $-2 \pi$ to 0 . Therefore, for every frequency $\omega_{i}$, the feedback specifications $\left\{\left|T_{k}\left(j \omega_{i}\right)\right| \leq \delta_{k}\left(\omega_{i}\right), k=1, \ldots, 5\right\}$ in Table I -Eqs. (4) to (9)are translated into the quadratic inequalities in Table II Eqs. (10) to (14)-, see [16]. The format of these quadratic expressions is:

$\mathrm{I}_{\omega_{\mathrm{i}}}^{\mathrm{k}}\left(\mathrm{p}, \theta, \delta_{\mathrm{k}}, \phi\right)=\mathrm{a} \mathrm{g}^{2}+\mathrm{bg}+\mathrm{c} \geq 0$

Chait and Yaniv [16] developed an algorithm to compute the bounds based on quadratic inequalities (see Table II), simplifying much of the work on traditional manual bound computation. Taking these inequalities into account, it is possible to compute them at the NC. Once the bounds have been calculated for the performance specifications, they have to be grouped into a single variable.
Then, the worst case bound, i.e. the most restrictive one for every phase, is computed for each frequency of the work array.

\section{4.- Controller design}

In the design stage (loop-shaping), the controller $\mathrm{G}(\mathrm{s})$ is synthesized on the $\mathrm{NC}$ by adding poles and zeros until the nominal loop, defined as $\mathrm{L}_{0}=\mathrm{P}_{0} \mathrm{G}$, lies near its bounds. Loop-shaping considers bounds on the $\mathrm{NC}$ to express the plant model with uncertainty and the performance specifications at every frequency.

An optimal controller will be obtained if it meets its bounds (over the continuous lines and under the dashed lines at every frequency) and it has the minimal high frequency gain, (see Fig.3).

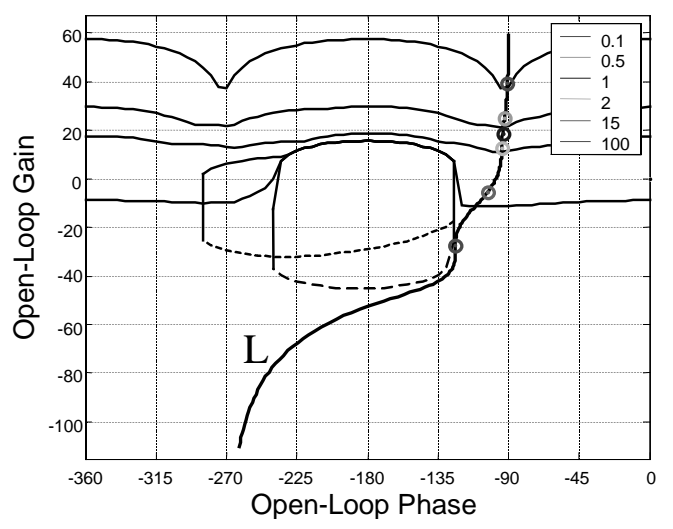

Figure 3.- Loop shaping

Although current CAD tools for QFT controller design are very helpful, the loop-shaping step must be still done manually using designer skills and experience. Even keeping the controller structure fixed, automatic tuning of parameters represents a great challenge.

The general formulation for the controller structure is expressed by the following transfer function:

\begin{tabular}{|l|c|c|}
\hline$k$ & Table II. Quadratic inequality on $\mathrm{g}$ & $E q$. \\
\hline 1 & $\mathrm{p}^{2}\left(1-\frac{1}{\delta_{1}^{2}}\right) \mathrm{g}^{2}+2 \mathrm{p} \cos (\phi+\theta) \mathrm{g}+1 \geq 0$ & $(10)$ \\
\hline 3 & $\mathrm{p}^{2} \mathrm{~g}^{2}+2 \mathrm{p} \cos (\phi+\theta) \mathrm{g}+\left(1-\frac{1}{\delta_{2}^{2}}\right) \geq 0$ & $(11)$ \\
\hline 4 & $\mathrm{p}^{2} \mathrm{~g}^{2}+2 \mathrm{p} \cos (\phi+\theta) \mathrm{g}+\left(1-\frac{\mathrm{p}^{2}}{\delta_{3}^{2}}\right) \geq 0$ & $(12)$ \\
\hline 5 & $\left(\mathrm{p}^{2}-\frac{1}{\delta_{4}^{2}}\right) \mathrm{g}^{2}+2 \mathrm{p} \cos (\phi+\theta) \mathrm{g}+1 \geq 0$ & $(13)$ \\
\hline
\end{tabular}




$$
G(s)=k_{G} \frac{\prod_{i=1}^{n_{r z}}\left(\frac{s}{z_{i}}+1\right) \prod_{i=1}^{n_{c z} / 2}\left(\frac{s^{2}}{\left|z_{i}\right|^{2}}+\frac{2 \operatorname{Re}\left(z_{i}\right)}{\left|z_{i}\right|^{2}} s+1\right)}{s^{r} \prod_{j=1}^{m_{r p}}\left(\frac{s}{p_{j}}+1\right) \prod_{j=1}^{m_{c p} / 2}\left(\frac{s^{2}}{\left|p_{j}\right|^{2}}+\frac{2 \operatorname{Re}\left(p_{j}\right)}{\left|p_{j}\right|^{2}} s+1\right)}
$$

where, $\mathrm{k}_{\mathrm{G}}$ is the gain, $\mathrm{z}_{\mathrm{i}}$ is a zero that may be complex $\left(\mathrm{n}_{\mathrm{cz}}\right.$, number of complex zeros) or real $\left(\mathrm{n}_{\mathrm{rz}}\right.$, number of real zeros), and $\mathrm{p}_{\mathrm{j}}$ is a pole (real or complex) with $\mathrm{m}_{\mathrm{rp}}$ the number of real poles and $\mathrm{m}_{\mathrm{cp}}$ the number of complex poles. Note that the amount of complex zeros or poles must be even, to have pairs of complex conjugate numbers and obtain a polynomial with real coefficients. Controller may have some poles in the origin and designer can check the parameter $r$ (usually 0,1 or 2 ) to set them.

\section{5.- Prefilter design}

If the feedback system involves tracking signals, then the best choice is to use a prefilter F. While controller G reduces the uncertainty and deals with stability, disturbance rejection, etc, prefilter $\mathrm{F}$ is designed to fulfil tracking requirements.

\section{6.- Analysis of the design}

Once the controller design is finished, it is necessary to analyse the behaviour of the system with the controller previously obtained. Closed-loop response at several frequencies and time domain responses must be checked. The analysis will be carried out with the most unfavourable cases due to uncertainty.

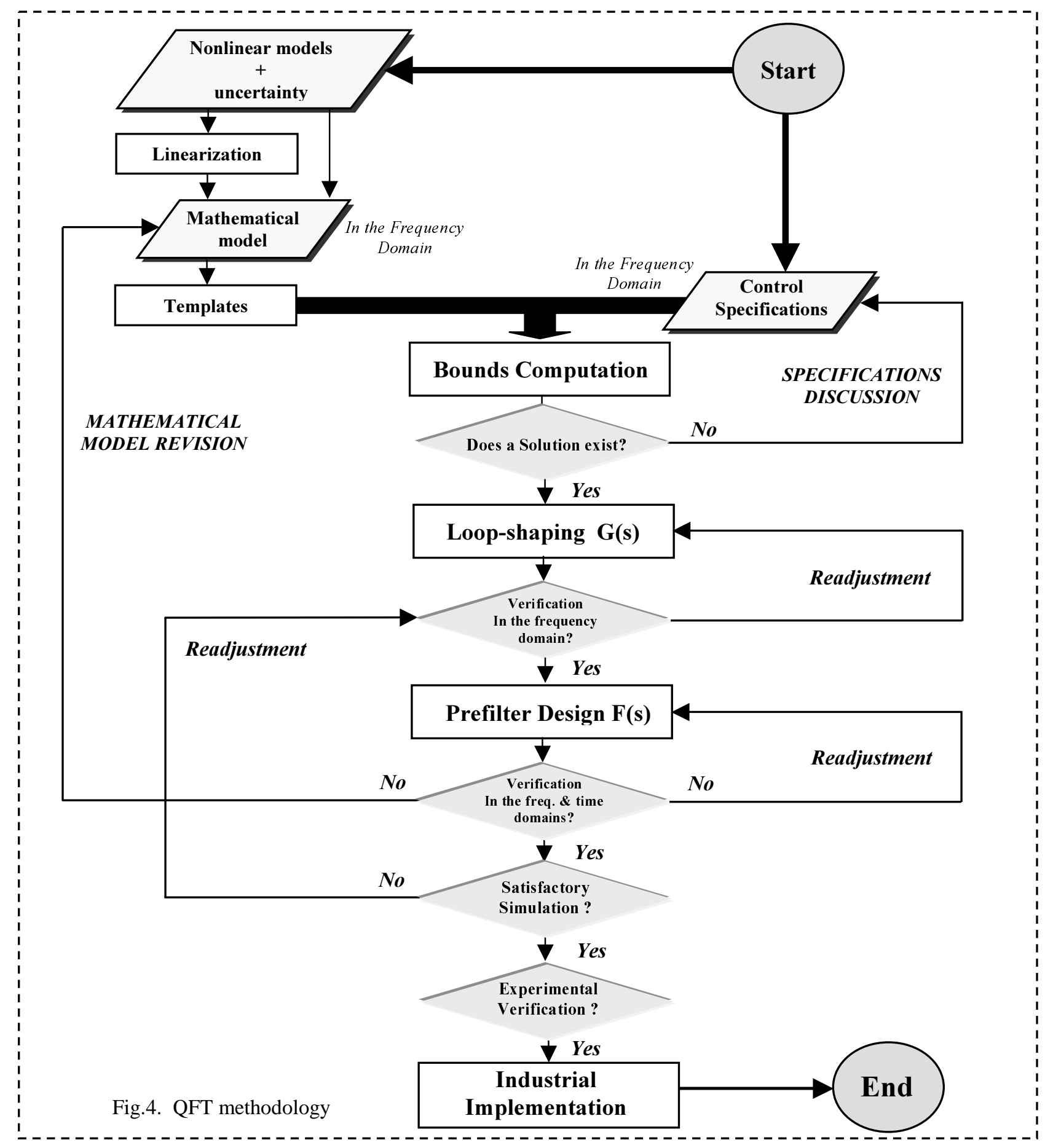




\section{The variable speed multipole wind turbine TWT1650}

This section presents the $1.65 \mathrm{MW}$ direct drive variable speed multipole wind turbine designed by M.Torres: the TWT1650 $[22,23]$ (see Figs. 5 and 6).

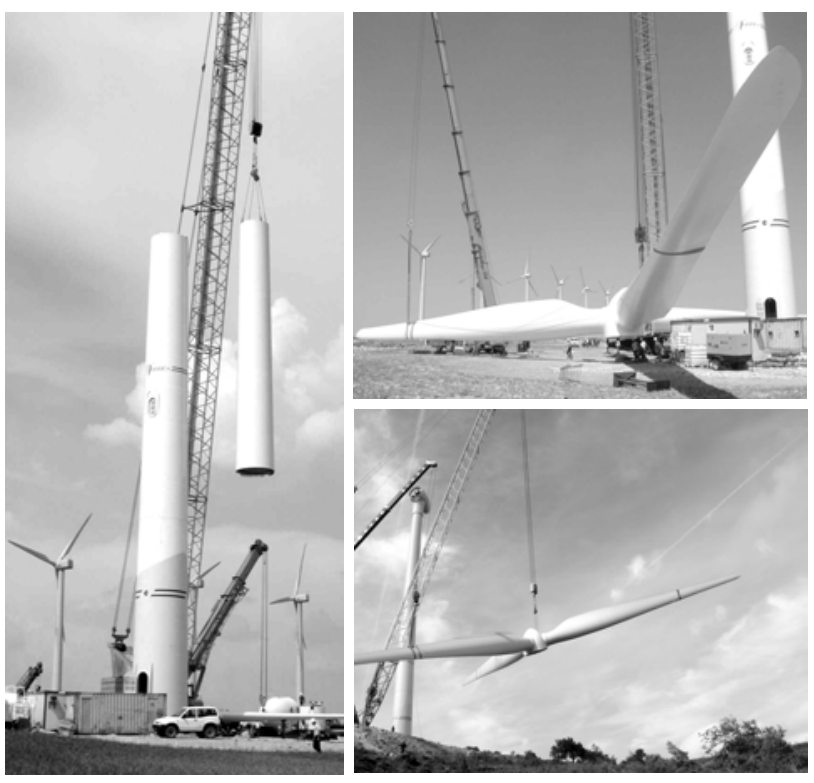

Fig.5. TWT1650 (M.Torres courtesy)

The design was optimised using finite element calculations, advanced electrical simulators and tacking into account the efficiency, reliability and power quality of the most critical elements of the system. In addition M.Torres developed a special real test bed for full power experimentation of the WT.

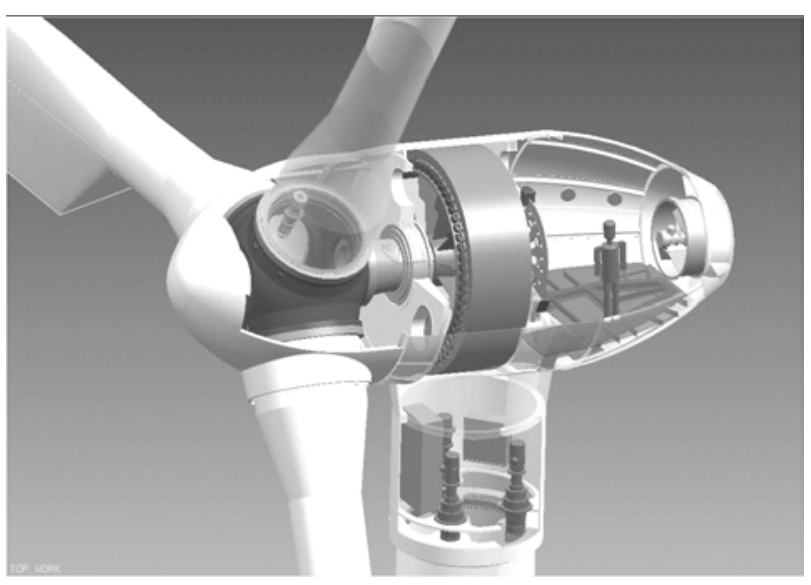

The main characteristics are described in Table III.

\begin{tabular}{|c|c|}
\hline Rotor & \\
\hline Diameter & $72 \mathrm{~m}$ \\
\hline Swept Area & $4072 \mathrm{~m}^{2}$ \\
\hline Number of Blades & 3 \\
\hline Position & Upwind \\
\hline Nominal Rotor Speed & $20 \mathrm{rpm}$ \\
\hline Range of Rotor Speed & Variable: 6 to $22 \mathrm{rpm}$ \\
\hline Pitch Control & $\begin{array}{l}\text { Pitch controlled with } 3 \\
\text { independent electrical } \\
\text { actuators }\end{array}$ \\
\hline \multicolumn{2}{|l|}{ Tower } \\
\hline Type & Tubular conical steel \\
\hline Hub height & $60 \mathrm{~m}$ \\
\hline Weight & $88000 \mathrm{Kg}$ \\
\hline Corrosion protection & Epoxy coating \\
\hline \multicolumn{2}{|l|}{ Operation data } \\
\hline Cut in wind speed & $3 \mathrm{~m} / \mathrm{s}$ \\
\hline Nominal wind speed & $12 \mathrm{~m} / \mathrm{s}$ \\
\hline Cut out wind speed (1) & $25 \mathrm{~m} / \mathrm{s}$ during $1 \mathrm{~min}$. \\
\hline Cut out wind speed (2) & $30 \mathrm{~m} / \mathrm{s}$ during $0.1 \mathrm{sec}$. \\
\hline Survival speed & $70 \mathrm{~m} / \mathrm{s}$ \\
\hline \multicolumn{2}{|l|}{ Generator } \\
\hline Type & $\begin{array}{l}\text { Direct Drive Multipole } \\
\text { Synchronous } \\
\text { Generator (M.Torres) }\end{array}$ \\
\hline Power to the grid & $1650 \mathrm{~kW}$ \\
\hline Voltage & $650 \mathrm{~V}$ \\
\hline \multicolumn{2}{|l|}{ Nacelle } \\
\hline Construction & Monocoque in steel \\
\hline Weight (rotor + hub) & $73000 \mathrm{Kg}$ \\
\hline Yaw Control & $\begin{array}{l}\text { Active system with } \\
\text { electrical drives }\end{array}$ \\
\hline Corrosion protection & Epoxy coating \\
\hline \multicolumn{2}{|l|}{ Power Electronics } \\
\hline Converters & $\begin{array}{l}\text { Two reversible IGBT } \\
\text { bridges }\end{array}$ \\
\hline Excitation & Independent \\
\hline \multicolumn{2}{|l|}{ Control System } \\
\hline Strategies & $\begin{array}{l}\text { QFT robust-adaptive- } \\
\text { predictive control }\end{array}$ \\
\hline High reliability & Redundant systems \\
\hline
\end{tabular}

Table III. TWT1650 Characteristics.

The electrical diagram of the TWT1650 is shown in Fig. 7. It has a two reversible IGBT bridges converters, and a $2000 \mathrm{~kW}$ multipole synchronous generator, also designed at MTorres.

Fig.6. TWT1650 (M.Torres courtesy)

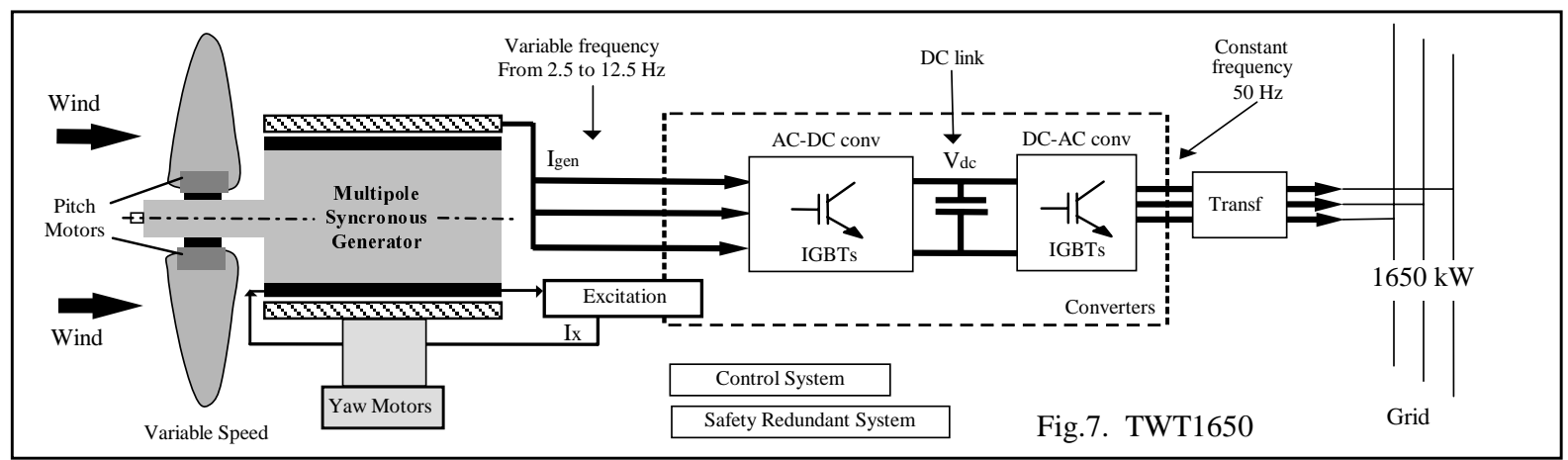




\section{TWT Control System}

Among the principal objectives of the central control system of the WT, it can be mentioned the improvement of the maximum power efficiency for every wind speed, the attenuation of the transient mechanical loads and fatigue stresses, the reduction of the electrical harmonics and flicker, and the robustness against parameters variation with a redundant fault tolerance system.

In addition some critical problems arise in the design of the WT control system, such as the difficulty to work safety with random and extreme gusts, the complexity introduced by the strongly nonlinear, multivariable and time variable mathematical model (see Eqs. 17 and 18 and Fig. 8) and the impossibility to have a direct measurement of the wind speed experienced by the turbine, because of the high uncertainty in the anemometer measurement and the strong influence of the blades movement [21].

$$
\begin{aligned}
& \mathrm{P}(\mathrm{t})=0.5 \rho \pi \mathrm{R}^{2} \eta \mathrm{C}_{\mathrm{p}} \mathrm{V}(\mathrm{t})^{3} \\
& \mathrm{C}_{\mathrm{p}}=\mathrm{f}_{\text {Non-linear }}(\mathrm{V}, \beta, \Omega, \mathrm{t})
\end{aligned}
$$

$\rho$ is the air density, $R$ the rotor radius, $C_{p}$ the aerodynamic coefficient, $\mathrm{V}$ the wind speed, $\eta$ the electrical and mechanical efficiency, $\beta$ the pitch angle, $\Omega$ the rotor speed, $\mathrm{P}$ the electrical power and $t$ the time.
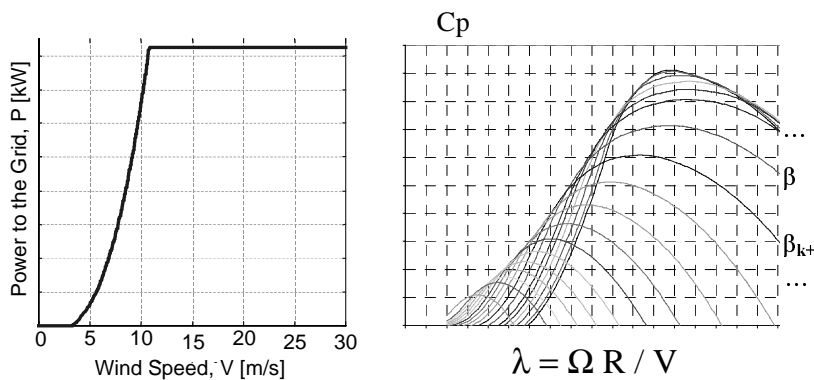

Fig.8. $\mathrm{P} / \mathrm{V}$ and $\mathrm{Cp} / \lambda$ curves.

These set of motivations obliged to combine advanced control strategies such us QFT robust control techniques (Quantitative Feedback Theory) [3-20], adaptive schemes, multivariable methodology [17] and predictive elements. M.Torres [23] developed the design of that complex control system in collaboration with an active research group in control engineering and QFT design [24].

Among other, it is necessary to control the Electrical Power, Torque, Rotational rotor speed, Pitch Angle and Pitch rotational speed (blades), Yaw angle, Power Factor, Generator current, Voltage DC bus, Current excitation, Temperatures, etc.

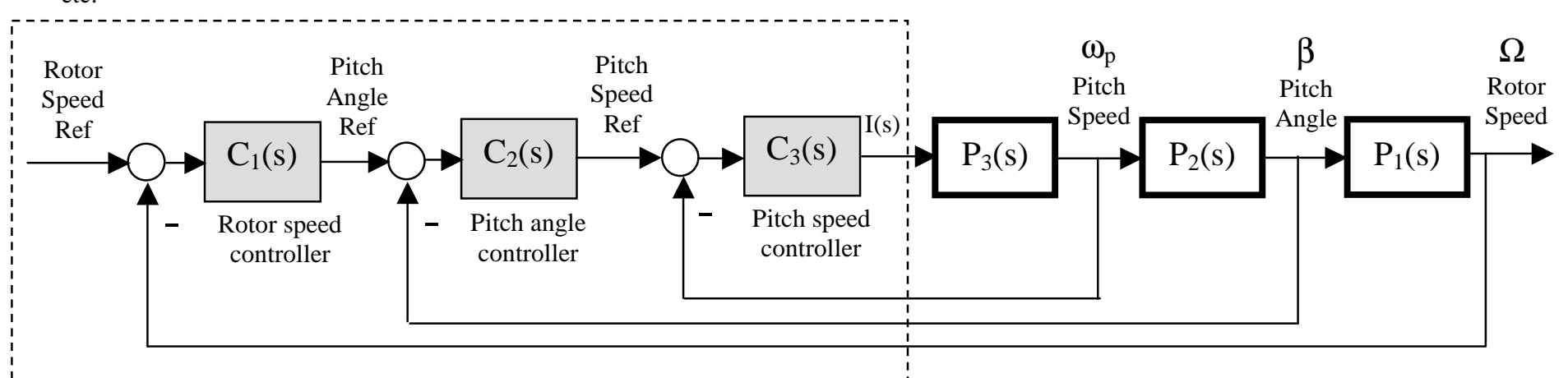

The pitch control system of a pitch regulated variable speed wind turbine aims to maintain the rotor speed within a permitted range in above rated wind speed. However, this requirement can be difficult to satisfy during extreme gusts with conventional controllers, particularly for large-scale machines where the pitch actuation capability may be quite limited.

This section investigates the actual results of the QFT robust controller with the $1.65 \mathrm{MW}$ variable speed turbine of M.Torres [22, 23], which directly responds to a strong gust by pitching the rotor blades. Fig. 9 shows the block diagram of the three cascade controllers use to control the rotor speed: Rotor Speed Controller $\mathrm{C}_{1}(\mathrm{~s})$, Pitch Angle Controller $\mathrm{C}_{2}(\mathrm{~s})$, and Pitch Speed Controller $\mathrm{C}_{3}(\mathrm{~s})$.

In this section two cases under very different wind conditions are shown: a very high wind speed case and a medium wind speed case.

Figs. 10 and 11 show experimental data of the TWT1650 Wind Turbine at Cabanillas Wind Farm (Spain). They present the performance of the WT under different wind speed conditions: the first one (6 April 2003) under very high wind speed (average $24 \mathrm{~m} / \mathrm{s}$, with excursions until $30 \mathrm{~m} / \mathrm{s}$ ); and the second one (4 February 2003) under medium wind speed (average 15 $\mathrm{m} / \mathrm{s}$, with excursions from $13 \mathrm{~m} / \mathrm{s}$ to $19 \mathrm{~m} / \mathrm{s}$ ).

In both cases the control system presents good performance behaviour, following correctly the rotor speed set point (20 $\mathrm{rpm}$ ) and rejecting the wind disturbances with a smooth movement of the blades.

The four parts of the figures are respectively: (a) the wind speed $-\mathrm{m} / \mathrm{s}-$ measured at the nacelle; (b) the rotor speed -rpm-; (c) the pitch angles (deg); and (d) the pith rotational speed deg/s-.

Figs. 10 and 11 show how the QFT robust-adaptive control strategies implemented in the WT are able to deal with very different operating points (from low to very high wind speed conditions), avoiding easily any possibility of over-speed.

Figs. (a) present the results of the rotor speed controller the three pitch angle controllers following the reference sent by the rotor speed controller. Figs. (c) show the results of the three pitch rotational speed controllers following the reference sent by the pitch angle controllers.

They reach a very good performance and a high reliability over the entire range of non-linear operation. following the reference at $20 \mathrm{rpm}$. Figs. (b) show the results of angle control and pitch speed control. 


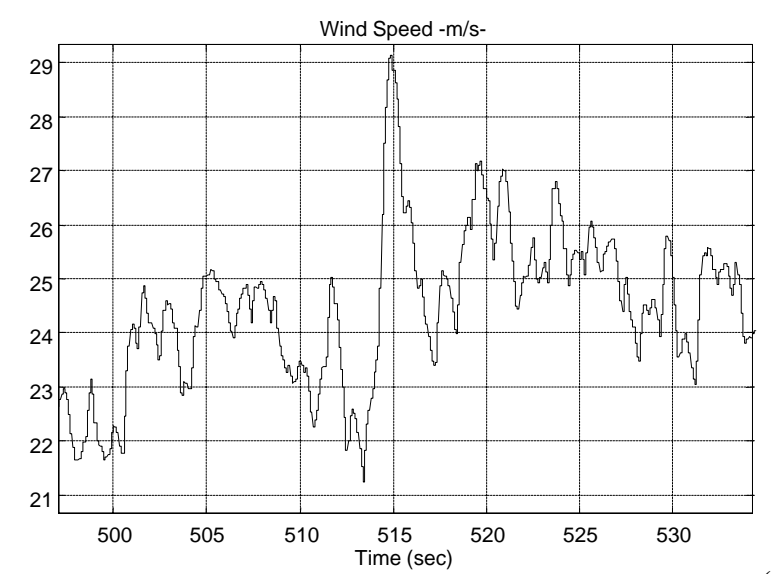

(a)

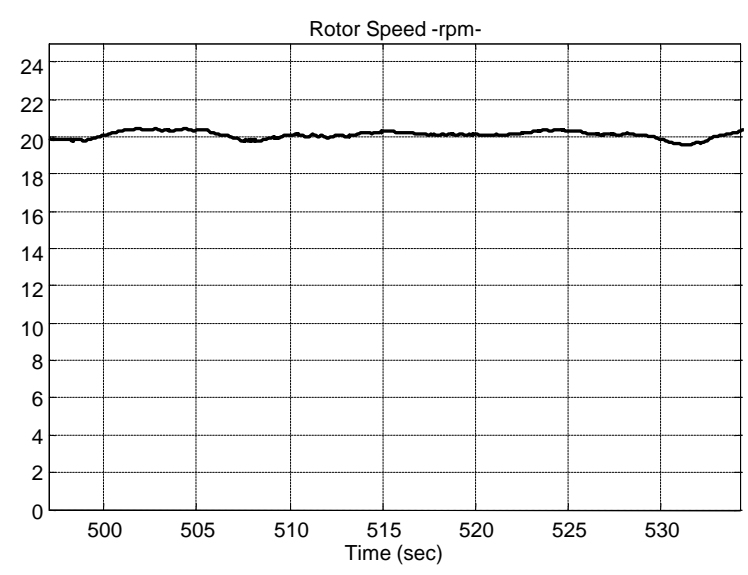

(b)

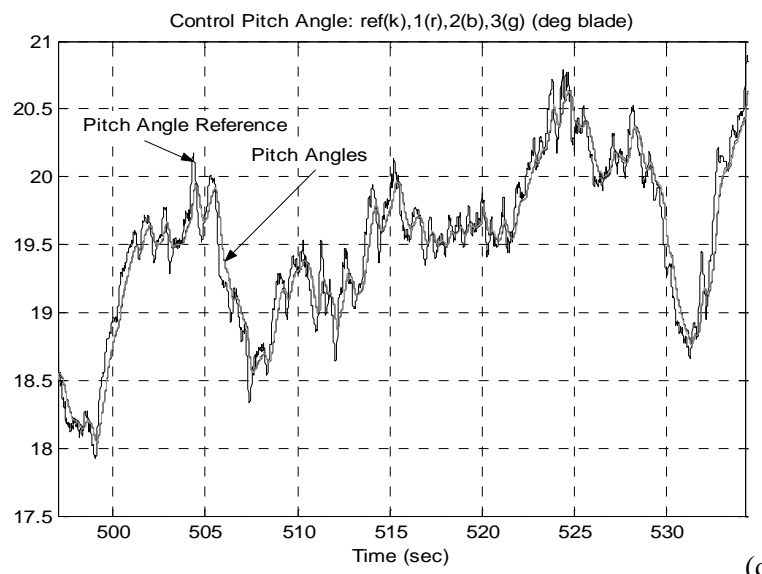

(c)

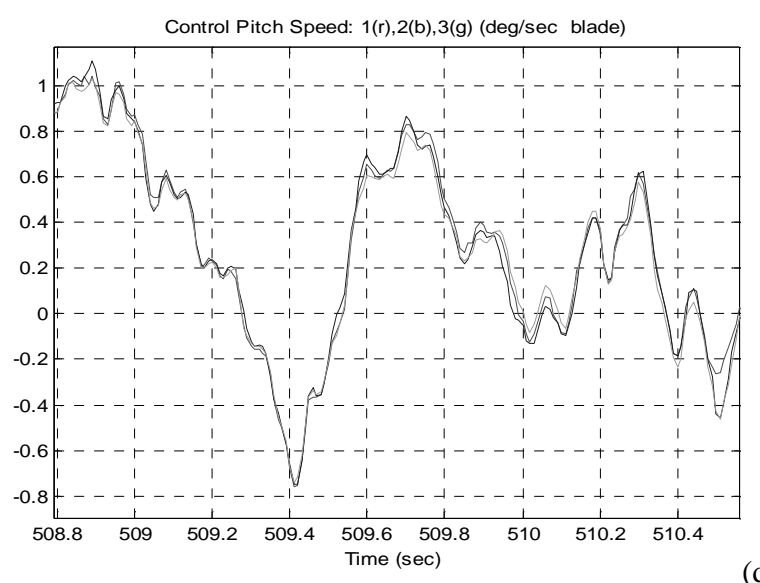

(d)

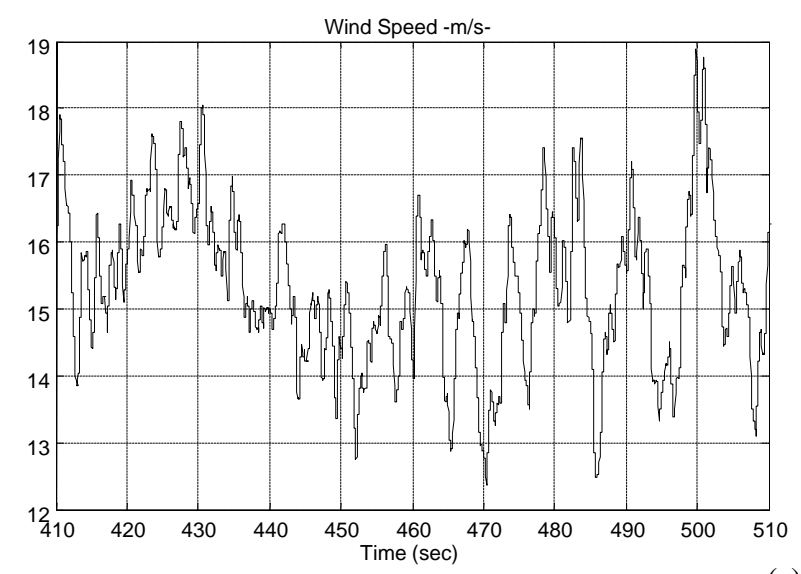

(a)

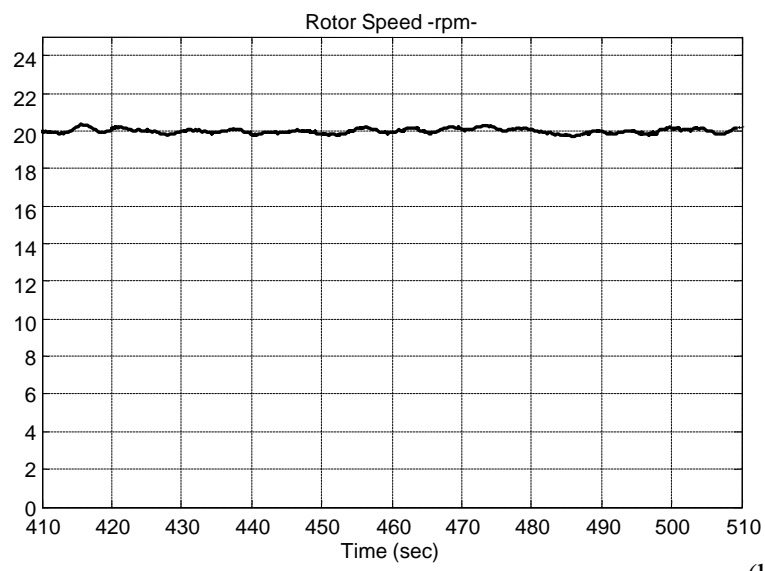

(b)

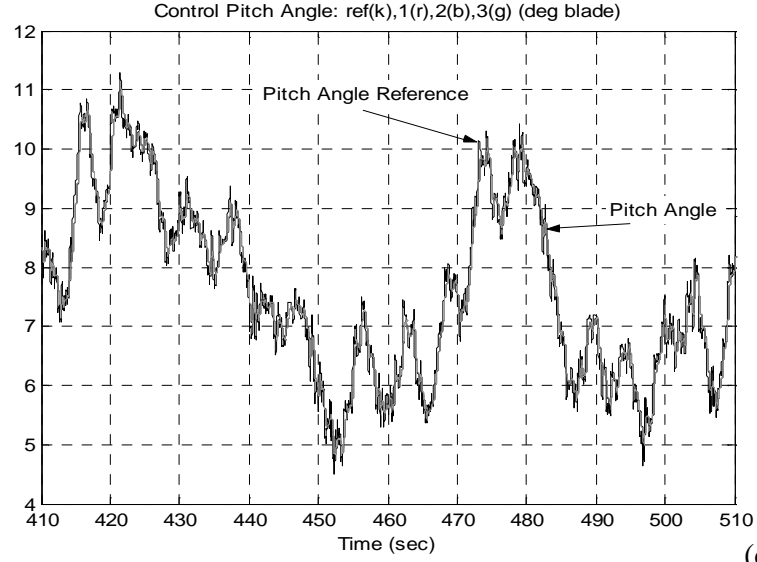

(c)

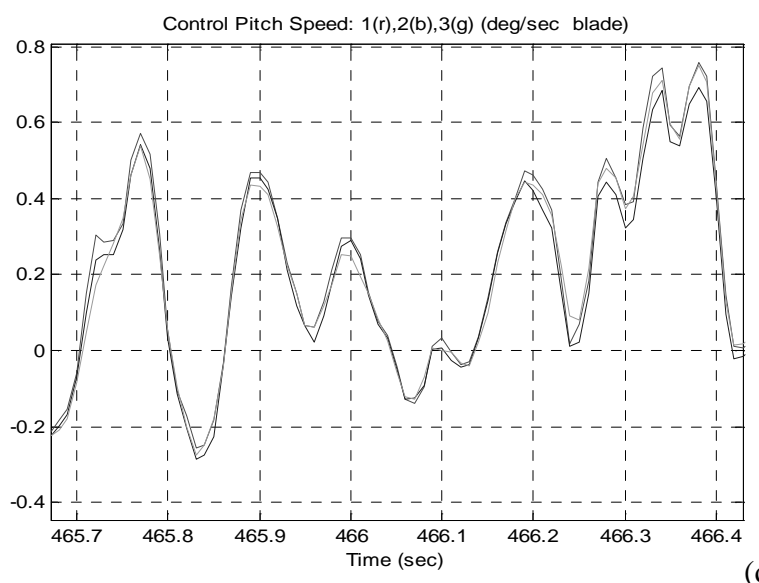

(d)

Fig.11. Control under medium wind speed conditions 


\section{Conclusions}

The first part of the paper presented a summary of the main concepts and references of the Quantitative Feedback Theory (QFT).

The second part described the new direct drive, variable speed, multipole wind turbine TWT1650, and shown some representative experimental results of the wind turbine in different wind speed conditions and controlled by the QFT robust control technique.

\section{Acknowledgement}

The author wish to gratefully appreciate the support given by the M.Torres Group and the Spanish "Ministerio de Ciencia y Tecnología" (MCyT) under grant CICYT DPI'2003-08580C02-01.

\section{References}

$\underline{\text { Books }}$

[1]. Bode H.W., (1945), Network Analysis and Feedback Amplifier Design. Van Nostrand Company.

[2]. Horowitz I., (1963), Synthesis of Feedback Systems (New York: Academic Press).

[3]. Horowitz I., (1993), Quantitative Feedback Design Theory (QFT). QFT Pub., 660 South Monaco Parkway, Denver, Colorado 80224-1229.

[4]. Houpis C.H. and Rassmussen S.J. (1999), Quantitative Feedback Theory: Fundamentals and Applications. Marcel Dekker: NY, USA.

[5]. Yaniv O., (1999), Quantitative Feedback Design of Linear and Non-linear Control Systems. Kluver Academic Pub., ISBN: 0-7923-8529-2.

[6]. Sidi M., (2002), Design of Robust Control Systems: From classical to modern practical approaches. Krieger Publishing.

\section{Special issues}

[7]. Houpis, C.H. (Guest Editor). Quantitative Feedback Theory Special Issue. International Journal of Robust and Nonlinear Control. Vol. 7, N. 6, June 1997. Wiley.

[8]. Eitelberg, Eduard (Guest Editor). Isaac Horowitz Special Issue. International Journal of Robust and Nonlinear Control. Part 1, Vol. 11, N. 10, August 2001 and Part 2, Vol. 12, N. 4, April 2002. Wiley.

[9]. Garcia-Sanz, Mario (Guest Editor). Robust Frequency Domain Special Issue. International Journal of Robust and Nonlinear Control. Vol. 13, June 2003. Wiley.

\section{International QFT Symposia}

[10]. Houpis C.H., Chander P. (Editors). $1^{\text {st }}$ Int. Symp. on Quantitative Feedback Theory and Robust Frequency Domain Methods, Writght Patterson Airforce Base, Dayton, Ohio, USA, August 1992.

[11]. Nwokah O.D.I., Chander P. (Editors). $2^{\text {nd }}$ Int. Symp. on Quantitative Feedback Theory and Robust Frequency
Domain Methods Purdue University, West Lafayette, Indiana, USA, August 1995.

[12]. Petropoulakis L., Leithead W.E.(Editors). $3^{\text {rd }}$ Int. Symp. on Quantitative Feedback Theory and Robust Frequency Domain Methods University of Strathclyde, Glasgow, Scotland, UK, August 1997.

[13]. Boje E., and Eitelberg E. (Editors). $4^{\text {tht }}$ Int. Symp. on Quantitative Feedback Theory and Robust Frequency Domain Methods University of Natal, Durban, South Africa, August 1999.

[14]. Garcia-Sanz M. (Editor). $5^{\text {th }}$ Int. Symp. on Quantitative Feedback Theory and Robust Frequency Domain Methods Public University of Navarra, Pamplona, Spain, August 2001.

[15]. Boje E., and Eitelberg E. (Editors). $6^{\text {th }}$ Int. Symp. on Quantitative Feedback Theory and Robust Frequency Domain Methods University of Cape Town, Cape Town, South Africa, December 2003.

Papers

[16]. Chait Y, and Yaniv O. (1993), Multi-input/single-output computer-aided control design using the Quantitative Feedback Theory. Int. J. Robust \& Non-linear Control, 1993, No.3, pp. 47-54.

[17]. Garcia-Sanz M. and Egaña I. (2002). Quantitative Nondiagonal Controller Design for Multivariable Systems with Uncertainty. Int. J. Robust \& Non-linear Control, Isaac Horowitz Special Issue, Part 2. March. 2002. N ${ }^{\circ}$ 12, pp. 321-333.

[18]. Horowitz I. and Sidi, M. (1972). Synthesis of feedback systems with large plant ignorance for prescribed timedomain tolerances, International Journal of Control, Vol. 16, No.2, pp. 287-309.

[19]. Horowitz, I., (1982), Quantitative feedback theory. IEE Control Theory and Applications, Vol. 129, pp. 215-226.

[20]. Horowitz,I.(1991). Survey of quantitative feedback theory. International Journal of Control, Vol. 53(2), pp. 255-291.

[21]. Leith D.J., and Leithead W.E., (1997), Implementation of Wind Turbine Controllers. International Journal of Control, Vol. 66, 349-380.

[22]. Torres E., and Garcia-Sanz M. (2004), Experimental Results of the Variable Speed, Direct Drive Multipole Synchronous Wind Turbine: TWT1650. To appear in Wind Energy 2004.

Ref.

[23]. M.Torres, Diseños Industriales S.A. (2004). http://www.mtorres.es

[24]. Control Engineering Group, CEG, Public Univ. of Navarra (2004). http://www.ayc.unavarra.es/ceg/home.htm 